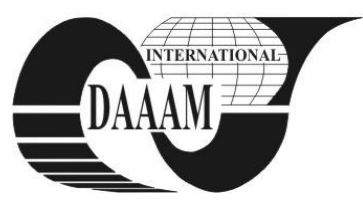

Annals of DAAAM for 2011 \& Proceedings of the 22nd International DAAAM Symposium, Volume 22, No. 1, ISSN 1726-9679 ISBN 978-3-901509-83-4, Editor B. Katalinic, Published by DAAAM International, Vienna, Austria, EU, 2011 Make Harmony between Technology and Nature, and Your Mind will Fly Free as a Bird Annals \& Proceedings of DAAAM International 2011

\title{
CONSIDERATIONS ON ADOPTING R 404A INSTEAD OF R22 ON REEFERS
}

\author{
MITU, D[aniela] - E[lena] \& MEMET, F[eiza] S[ucuran]
}

\begin{abstract}
R 22$ is one of the dominant refrigerants for marine applications. This refrigerant is a HCFC chemical; its substitution in the marine sector demands efforts done to indicate the right refrigerant. On reefers (refrigerated ships), the substitutes for $R 22$ are $R 410 \mathrm{~A}, R 407 \mathrm{C}$ and $R 404 \mathrm{~A}$, since a single ideal refrigerant is not nominated. Available literature shows that $R 404 \mathrm{~A}$ can be used in best conditions as a substitute for $R$ 22. Thus, in this paper is given a comparison between $R 22$ and $R 404$ A resulting alike properties. In time of crisis, the maintenance of the existing $R 22$ equipment provides an economic benefit. This study deals also with the retrofit aspect
\end{abstract}

Key words: reefers, friendly environmental refrigerant, property, equipment

\section{INTRODUCTION}

Reefer transport is defined as the maritime transport of perishable cargo that asks climate control during transport in order to reduce product deterioration. Emitted CFC and HCFC refrigerants have been directly connected to the destruction of stratospheric ozone. International regulations have been adopted in order to phase out the production and consumption of the refrigerants for the protection of the stratospheric ozone layer.

All marine refrigerating systems working with R22 cannot be maintained, serviced or topped up with new refrigerant after January 1, 2010. Between January 1, 2010 and January 1, 2015, recycled HCFC may be used. After January 1, 2015, the use of HCFCs is completely banned on E.U. flagged vessels.

\section{THE ENVIRONMENTAL ISSUE}

The vast majority of marine refrigerating equipment is vapour compression systems that use ozone depleting substances like CFCs and HCFCs. Refrigerants like CFCs, HCFCs and HFCs are potent greenhouse gases.

\subsection{About the ozone layer}

The Convention signed in Vienna (1985) pointed out the need of the progressive phase-out of ozone depleting substances, contributing to the signing of the Montreal Protocol, in 1987. In the following 15 years, this Protocol was signed by several stakeholders, being quickly implemented due to the involvement of governments, industrial stakeholders, manufacturers and users of refrigerants.

The Protocol started research works in order to be found new refrigerants, the so called "green refrigerants", having no impact on the ozone layer (like HCFCs). Also, some works focused on the rediscover of forgotten refrigerants (like $\mathrm{NH}_{3}$ and $\mathrm{CO}_{2}$ ), that might be successfully used with some technical improvements.

HCFCs are mild Ozone Depleting Substances as compared to CFCs. Their ODS potential is only about $5 \%$ of that CFCs (Spatz \& Soffientini, 2010).

\begin{tabular}{|l|l|c|}
\hline Family of refrigerants & \multicolumn{1}{|c|}{ Main refrigerants } & ODP \\
\hline CFCs & CFC 11 (R 11) & 1 \\
& CFC 12 (R 12) & 1 \\
\hline HCFCs & HCFC 22 (R 22) & 0,05 \\
\hline HFCs & HFC 134 a (R 134 a) & 0 \\
& HFC 404 A (R 404 A) & 0 \\
& HFC 407 C (R 407 C) & 0 \\
& HFC 410A (R 410 A) & 0 \\
\hline Natural refrigerants & $\mathrm{NH}_{3}$ (R 717) & 0 \\
& $\mathrm{CO}_{2}$ (R 744) & 0 \\
& Hydrocarbons & 0 \\
\hline
\end{tabular}

Tab.1. Refrigerants' impact on the ozone layer

HCFCs phase out helps ozone layer protection as well as climate change, but more than that it helps the economy. The impact of some refrigerants on the ozone layer is given in Table 1.

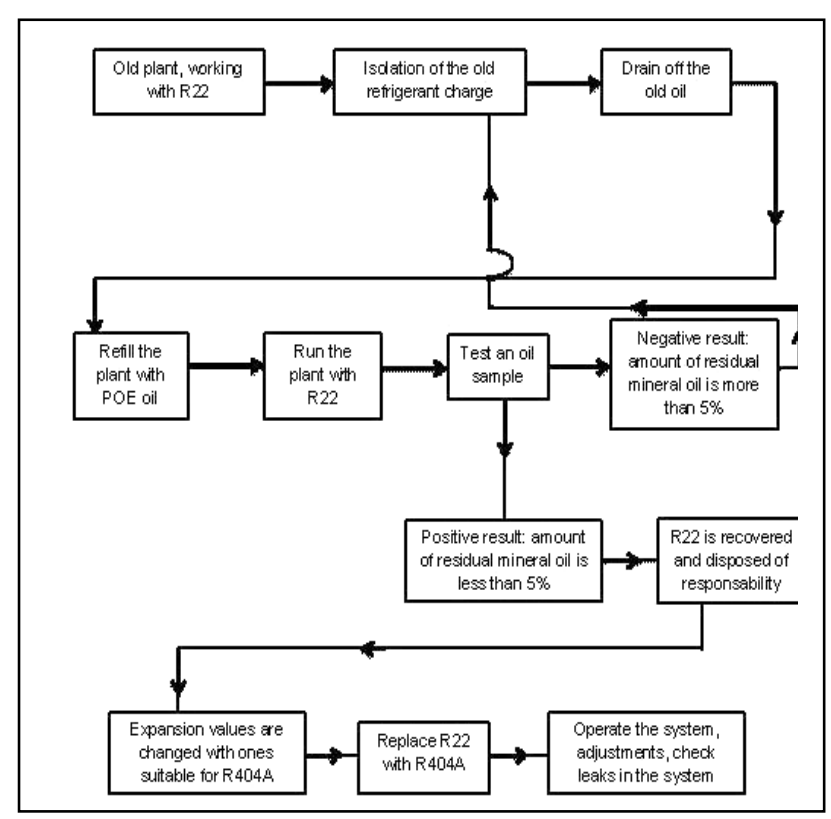

Fig. 1. Chart of the R22 replacement with R404A

\subsection{Global warming}

Rising global temperature measurements and their correlation with the increase in $\mathrm{CO}_{2}$ in the atmosphere led researches to observe that human activity release gases that significantly increased the natural greenhouse effect around the Earth. This situation led to the signing of the Rio Convention, in 1992, then the Kyoto Protocol in 1997. CFCs have been replaced by HCFCs. These also have an ozone depleting and a global warming potential, but much lower. Other substitutes are HFCs. These have only a global warming potential (GWP), very close to the GWP of HCFCs, on the average. These replacements revealed a diminishing of more than $25 \%$ of global greenhouse emissions compared to 1990. The main 
concerns of the marine refrigerating sector might be resumed to the reduction of the direct effect of refrigerant emissions and the reduction in the energy consumption of the refrigeration systems (Memet \& Mitu, 2010). The impact of some refrigerant on the global warming is given in Table 2 .

\begin{tabular}{|l|l|c|}
\hline Family of refrigerants & Main refrigerants & GWP \\
\hline CFCs & CFC 11 (R 11) & 4750 \\
& CFC 12 (R 12) & 10890 \\
\hline HCFCs & HCFC 22 (R 22) & 1810 \\
\hline HFCs & HFC 134 a (R 134 a) & 1430 \\
& HFC 404 A (R 404 A) & 3900 \\
& HFC 410A (R 410 A) & 2100 \\
\hline Natural refrigerants & $\mathrm{NH}_{3}$ (R 717) & $<1$ \\
& $\mathrm{CO}_{2}$ (R 744) & 1 \\
& Hydrocarbons & 20 \\
& Water & 0 \\
\hline
\end{tabular}

Tab. 2. Refrigerants' impact on the global warming

For the two widely spread R 12 and R 22 in marine refrigeration, the time schedule of Montreal Protocol is as follows:

\begin{tabular}{|c|c|c|}
\hline Refrigerants & $\begin{array}{c}\text { Industrialized } \\
\text { countries }\end{array}$ & $\begin{array}{c}\text { Developing } \\
\text { countries }\end{array}$ \\
\hline CFC 12 (R 12) & $\begin{array}{c}\text { Forbidden since } \\
1996\end{array}$ & $\begin{array}{c}\text { Forbidden in } \\
2010\end{array}$ \\
\hline CFC 22 (R 22) & Forbidden in 2020 & Forbidden in \\
& & 2030 \\
\hline
\end{tabular}

Tab. 3. Regulations of the Montreal Protocol

\section{KEEPING THE EXISTING EQUIPMENTS IN THE REFRIGERATING TRANSPORT}

A wise option in time of crisis is keeping the existing plant and replacing R22 with a HFC refrigerant. This inexpensive solution is not available for all HFCs, but might be adopted when choosing R404A, a HFC which dominates the refrigerated transport. The replacement of R22 in this case can be followed according for the chart depicted in Figure 1.

$\mathrm{R} 404 \mathrm{~A}$ is a chlorine free mixture, able to replace HCFCs in refrigerated transportation. It is defined by the components R125/R134a/R143a (mass\%: 44, 4; 52). Discussing about the most encountered HCFC retrofitting case in the refrigerated transport, meaning R22 to be changed by R404A, the comparison between thermal and energetic performances can be seen in Tables 4-8. R 404 A's vapor pressure is slightly higher than R 22 making it a potential choice for retrofitting existing equipment; the thermodynamic cycle efficiency is similar in both cases. Specific refrigerated capacity and specific mechanical work have comparable values, making also the retrofitting possible. Heat transfer analysis shows slightly lower performances for R 404 A (Spatz \&Soffientini, 2010).

\begin{tabular}{|l|c|c|}
\hline $\begin{array}{c}\text { Evaporating temperature } \mathbf{- 3 5}^{\mathbf{0}} \mathbf{C} ; \\
\text { Condensing temperature } \mathbf{- 3 5}^{\mathbf{C}} \mathbf{C}\end{array}$ & $\mathbf{R ~ 2 2}$ & $\mathbf{R ~ 4 0 4 A}$ \\
\hline Discharge pressure $($ bar $)$ & 14,07 & 16,78 \\
\hline Discharge temp $\left({ }^{0} \mathrm{C}\right)$ & 197,0 & 123,5 \\
\hline Cooling capacity $\left(\mathrm{KJ} / \mathrm{m}^{3}\right)$ & 619 & 705 \\
\hline$\%$ of R-22 & 100 & 114 \\
\hline COP & 1,27 & 1,27 \\
\hline Compression ratio & 11,4 & 10,7 \\
\hline Temperature glide $\left({ }^{0} \mathrm{C}\right)$ & 0 & 0,5 \\
\hline Flow rate & 5,67 & 7,57 \\
\hline Mineral oil & Yes & No \\
\hline POE & Yes & Yes \\
\hline
\end{tabular}

Tab. 4. Comparative performances in refrigeration

\begin{tabular}{|c|c|c|c|c|}
\hline \multirow{2}{*}{$\mathbf{t}_{\mathbf{o}}$} & \multicolumn{2}{|c|}{$\begin{array}{c}\text { Specific refrigerated } \\
\text { capacity }\end{array}$} & \multicolumn{2}{c|}{$\begin{array}{c}\text { Specific mechanical } \\
\text { work }\end{array}$} \\
\cline { 2 - 5 } & $\mathbf{R 2 2}$ & $\mathbf{R 4 0 4 A}$ & $\mathbf{R 2 2}$ & $\mathbf{R 4 0 4 A}$ \\
\hline-40 & 652 & 550 & 382 & 358 \\
\hline-30 & 1000 & 803 & 518 & 450 \\
\hline-20 & 1550 & 1249 & 614 & 545 \\
\hline-10 & 2500 & 2002 & 709 & 654 \\
\hline
\end{tabular}

Tab. 5. Thermal properties of R22 an R404A, for different evaporating temperatures

\begin{tabular}{|c|c|c|}
\hline $\mathbf{t}_{\mathbf{0}}{ }^{\mathbf{0}} \mathbf{C}$ & $\mathbf{t}_{\mathbf{c}} \mathbf{}^{\mathbf{C}}$ & Deviation, \% \\
\hline-10 & 50 & 16,2 \\
\hline-20 & 45 & 14,2 \\
\hline-30 & 40 & 11,3 \\
\hline-40 & 35 & 10,6 \\
\hline
\end{tabular}

Tab. 6. Deviation of specific energy consumption - comparison between R22 and R404A

\begin{tabular}{|l|c|c|c|c|c|}
\hline \multicolumn{1}{|c|}{$\begin{array}{c}\text { Mass flux (Kg/ } \\
\left.\mathbf{m}^{2} \mathbf{s}\right)\end{array}$} & $\mathbf{8 0}$ & $\mathbf{1 8 0}$ & $\mathbf{2 8 0}$ & $\mathbf{3 8 0}$ & $\mathbf{4 8 0}$ \\
\hline R 22 & 4000 & 5800 & 7300 & 8000 & 9700 \\
\hline R 404 A & 3840 & 4600 & 5900 & 6300 & 7000 \\
\hline
\end{tabular}

Tab. 7. Average evaporation coefficient for a tube diameter of 8 $\mathrm{mm}$ and an evaporation temperature of $267 \mathrm{~K}$

\begin{tabular}{|l|c|c|c|c|c|}
\hline $\begin{array}{c}\text { Mass flux(Kg/ } \\
\left.\mathbf{m}^{2} \mathbf{s}\right)\end{array}$ & $\mathbf{8 0}$ & $\mathbf{1 8 0}$ & $\mathbf{2 8 0}$ & $\mathbf{3 8 0}$ & $\mathbf{4 8 0}$ \\
\hline R 22 & 1000 & 1800 & 2500 & 2900 & 3800 \\
\hline R 404 A & 980 & 1200 & 1800 & 2500 & 3000 \\
\hline
\end{tabular}

Tab. 8. Average condensation coefficient for a tube diameter of $8 \mathrm{~mm}$ and a condensation temperature of $317 \mathrm{~K}$

\section{CONCLUSION}

Refrigerated transport is an essential activity for our society. International regulations determined this sector to action in order to replace $\mathrm{R} 22$, a spread hydro chlorofluorocarbon (HCFC) from the specific equipments. Presented comparison indicates thermodynamic similarity between R 22 and R 404 A.

Keeping the existing equipments in the refrigerating transport is a cheap solution in time of crisis, available for $\mathrm{R}$ $404 \mathrm{~A}$, but not for all HFCs. It was given steps to be followed for the replacement of R 22 with R 404 A.

\section{REFERENCES}

Chakroun, W.M. (2009). Ashrae positions to meet future environmental challenges, Proceedings of the XIII European Conference in Latest Technologies in Refrigeration and Air Conditioning, Milan, Italy

Garcia, L.R. (2008). Development of monitoring applications for refrigerated perishable goods transportation, Ph.D. thesis, pp 198, Universidad Politecnica de Madrid, Spain

Memet, F. \& Mitu, D. - E. (2010). Exergetic and environmental analysis when using R 407C in marine refrigeration (2010). 0939-0941, Annals of DAAAM for 2010 \& Proceedings of the 21st International DAAAM Symposium, ISBN 978-3901509-73-5, ISSN 1726-9679, pp 0470, Editor B. Katalinic, Published by DAAAM International, Vienna, Austria 2010

Spatz, M.W.; Soffientini, C.G.A. (2001). Evaluation of HCFC22 replacements characteristics and air conditioning \& heat pump systems performances in relation to energy efficiency and total environmental impact, Clima 2000 World Congress, Napoli, 2001

United Nation Industrial Development Organization (2009). Preparing for HCFC phase - out: Fundamentals of uses, alternatives, implications and funding for Article 5 countries, 199pp, 2009, Vienna, Austria 